\title{
Use of social media by b2b companies: systematic literature review and suggestions for future research
}

\author{
Yogesh Dwivedi ${ }^{1}$, Elvira Ismagiloiva ${ }^{2}$, Nripendra Rana ${ }^{1}$, Vishanth Weerakkody ${ }^{2}$ \\ ${ }^{1}$ Emerging Markets Research Centre, School of Management, Swansea University, UK \\ \{y.k.dwivedi, n.p.rana\}@ swansea.ac.uk \\ ${ }^{2}$ Faculty of Management, Law and Social Sciences, University of Bradford, Bradford, UK \\ \{e.ismagilova, v.weerakkody\}@bradford.ac.uk
}

\begin{abstract}
Social media plays an important role in the digital transformation of businesses. This research provides a comprehensive analysis of the use of social media by b2b companies. The current study focuses on a number of aspects of social media such as: the effect of social media; social media tools; social media use; adoption of social media use and its barriers; social media strategies; and measuring the effectiveness of the use of social media. This research provides a valuable synthesis of the relevant literature on social media in the $b 2 b$ context by analysing and discussing the key findings from existing research on social media. The findings of this study can be used as an informative framework on social media for both academics and practitioners.
\end{abstract}

Keywords: Social media; B2B; Literature review

\section{Introduction}

The Internet has changed social communications and social behaviour, in turn leading to the development of new forms of communication channels and platforms [1]. Social media plays an important role in the digital transformation of businesses. Whereas, in the past, social networks were used to provide information about a company or brand, nowadays businesses use social media to support their marketing aims and strategies to improve consumer's involvement, relationship with customers and to get useful consumers' insights [2]. Business to consumer (b2c) companies widely use social media and enjoy its benefits such as an increase in sales, brand awareness, and customer engagement to name a few [3].

More recently, business to business (b2b) companies started using social media as part of their marketing strategy. Even though b2b companies are benefitting from social media used by marketers, it is argued that research on that area is still in the embryonic stage and future research is needed [4-6].

The topic of Social media in the context of b2b companies has started to attract attention from both academics and practitioners. This is evidenced by the growing number of research output within academic journals and conference proceedings. Some studies provided a comprehensive literature review on social media use by $b 2 b$ 
companies $[4,7]$, but focused only on the adoption of social media by b2b or social media influence, without providing the whole picture of the use of social media by b2b companies. Thus, this study aims to close this gap in the literature by conducting a comprehensive analysis of the use of social media by $b 2 b$ companies. The findings of this study can provide an informative framework for research on social media in the context of $\mathrm{b} 2 \mathrm{~b}$ companies for academics and practitioners.

The remaining sections of the study are organised as follows. Section 2 offers a brief overview of the methods used to identify relevant studies to be included in this review. Section 3 synthesises the studies identified in the previous section and provides their detailed overview. Section 4 presents limitations of current studies on social media use by b2b companies and outlines directions for future research. Finally, section 4 discusses the key aspects of the research, outlining limitations of the current research and proposing direction for future research.

\section{$2 \quad$ Literature search method}

This study used a keyword search based approach for identifying relevant articles [8, 9]. Keywords such as "Advertising" OR "Marketing" OR "Sales" AND TITLE ( "Social Media" OR "Web 2.0" OR "Facebook" OR "LinkedIn" OR "Instagram" OR "Twitter" OR "Snapchat" OR "Pinterest" OR "WhatsApp" OR "Social Networking Sites" ) AND TITLE-ABS-KEY ("B2B" OR "B to B" OR "Business to Business" OR "Business 2 Business") were searched via the Scopus database. Only results in English language were included. All studies were processed by the authors in order to ensure relevance and that the research offered a contribution to the social media in the context b2b discussion. The search and review resulted in 70 articles and conference papers that formed the literature review for this study. The selected studies appeared in 33 separate journals and conference proceedings, including Industrial Marketing Management Journal, Journal of Business and Industrial Marketing and Journal of Business research.

\section{$3 \quad$ Literature synthesis}

The studies on the use of social media by b2b companies were divided into the following themes: effect of social media, social media tools, social media use, adoption and barriers of social media use, social media strategies, and measuring the effectiveness of the use of social media (see Table 1). The following subsections provide an overview of each theme.

Table 1. Themes in social media research $(\mathrm{b} 2 \mathrm{~b} \text { context })^{*}$

\begin{tabular}{|l|l|}
\hline \multicolumn{1}{|c|}{ Theme } & \multicolumn{1}{c|}{ Studies } \\
\hline Effect of social media & {$[10-15]$} \\
\hline Social media tools & {$[16-18]$} \\
\hline
\end{tabular}




\begin{tabular}{|l|l|}
\hline Social media use & {$[19][20][21][22]$} \\
\hline Adoption of social media use & {$[5,23-26]$} \\
\hline Social media strategies & {$[27-30]$} \\
\hline Measuring effectiveness of use of SM & {$[5,31]$} \\
\hline
\end{tabular}

* Note: just some studies out of 70 were included in this review due to the page limit. The full list of studies can be requested from authors.

\subsection{Effect of social media}

Some studies focus on the effect of social media for $\mathrm{b} 2 \mathrm{~b}$ companies which include customer satisfaction, value creation, post sales service behavior, sales, building relationships with customers, brand awareness, intention to purchase, knowledge creation, perceived corporate credibility, acquiring of new customers, salesperson performance and employee brand engagement. For example, Agnihotri et al. [10] investigated how the implementation of social media by b2b salesperson affects consumer satisfaction. Salesperson social media use is defined as a "salesperson's utilization and integration of social media technology to perform his or her job" [10]. The study used data of 111 sales professionals involved in $\mathrm{b} 2 \mathrm{~b}$ industrial selling to test the proposed hypotheses. It was found that a salesperson's use of social media will have a positive effect on information communication, which will, in turn, lead to improved customer satisfaction with the salesperson. Also, it was investigated that information communication will be positively related to responsiveness, which impacts customer satisfaction.

Another study by Kho [32] states the advantages of using social media by B2B companies, which include faster and more personalised communications between customer and vendor, which can improve corporate credibility and strengthen the relationships. Thanks to social media companies can provide more detailed information about their products and services. Kho [32] also mentions that customer forums and blog comments in b2b environment should be carefully monitored in order to make sure that inappropriate discussions are taken offline and negative eWOM communications should be addressed in a timely manner.

Another group of studies investigated the effect of social media on the level of sales. For example, Itani et al. [13] use theory of reasoned actions to develop a model that tests the factors affecting the use of social media by a sales person and its impact. By collecting data from 120 salespersons from different industries and using SmartPLS to analyse the data, it was found that attitude towards social media usefulness did not affect the use of social media. It was found that social media use positively affects competitive intelligence collection, adaptive selling behaviour which in turn influenced sales performance. The study conducted by Rodriguez et al. [15] examines the effect of social media on b2b sales performance by using social capital theory and collecting data from $1699 \mathrm{~b} 2 \mathrm{~b}$ salespeople from over 25 different industries. By employing SEM Amos the study found that social media usage has a positive significant relationship with selling companies' ability to create opportunities and manage relationships. The study also found that social media usage has a positive and significant relationship with sales performance (based on relational measurers of sales that focus on behaviours that strengthen the relationship between buyers and sellers), but not 
with outcome-based sales performance (reflected by quota achievement, growth in average billing size, and overall revenue gain).

Some researchers argued that social media can influence brand awareness. For instance, Hsiao et al. [12] investigated the effect of social media in fashion industry. By collecting 1395 posts from lookbook.nu and employing regression analysis it was found that inclusion national brand and private fashion brands in the post increased the level of popularity which lead to purchase interest and brand awareness.

Meire et al. [14] investigated the impact of social media on acquiring B2B customers. By using commercially purchased prospecting data, website data and Facebook data from beverage companies the study conducted an experiment and found that social media us an effective tool in acquiring B2B customers.

Agnihotri et al. [11] proposed theoretical framework to explain the mechanisms through which salespeople's use of social media operates to create value, and propose a strategic approach to social media use to achieve competitive goals. The proposed framework describes how social media tools can help salespeople perform service behaviours leading to value creation.

\subsection{Adoption of social media}

Some scholars investigated factors affecting the adoption of social media by $b 2 b$ companies. For instance, Lacka and Chong [23] investigated factors affecting the adoption of social media by $b 2 b$ companies from different industries in China. The study collected the data from 181 respondents and used the Technology Acceptance Model with Nielsen's Model of Attributes of System Acceptability as a theoretical framework. By using SEM Amos for analysis the study found that perceived usability, perceived usefulness, and perceived utility positively affect the adoption and use of social media by b2b marketing professionals. The usefulness is subject to the assessment of whether social media sites are suitable means through which marketing activities can be conducted. The ability to use social media sites for B2B marketing purposes, in turn, is due to those sites learnability and memorability attributes.

Lashgari et al. [24] studied the adoption and use of social media by using face-toface interviews with key managers of four multinational corporations and observations from companies' websites and social media platforms. It was found that the elements essential in forming the B2B firm's social media adoption strategies are content (depth and diversity), corresponding social media platform, structure of social media channels, the role of moderators, information accessibility approaches (public vs. gated-content), and online communities. These elements are customised to the goals and target group the firm sets to pursue. Similarly, integration of social media into other promotional channels can fall under an ad-hoc or continuous approach depending on the scope and the breadth of the communication plan, derived from the goal.

Another study by Müller et al. [25] investigated factors affecting the usage of social media. By using survey data from 100 polish and 39 German sensor suppliers, it was found that buying frequency, the function of a buyer, the industry sector and the 
country does not affect the usage of social media in the context of sensor technology from Poland and Germany. The study used correlation analysis and ANOVA.

Shaltoni [26] applied technology organisational environmental framework and diffusion of innovations to investigate factors affecting the adoption of social media by b2b companies. By using data from marketing managers or business owners of 480 SMEs, the study found that perceived relative advance, perceive compatibility, organizational innovativeness competitor pressure and customer pressure influence the adoption of social media by b2b companies. The findings also suggest that many decision makers in $\mathrm{b} 2 \mathrm{~b}$ companies think that internet marketing is not beneficial, as it is not compatible with the nature of $b 2 b$ markets.

While most of the studies focused on the antecedents of social media adoption by b2b companies, Michaelidou et al. [5] investigated its perceived barriers. By using data from 92 SMEs the study found that over a quarter of B2B SMEs in the UK are currently using SNS to achieve brand objectives, the most popular of which is to attract new customers. The barriers that prevent SMEs from using social media to support their brands were lack of staff familiarity and technical skills. Innovativeness of a company determined the adoption of social media.

\subsection{Social media strategies}

Another group of studies investigated types of strategies b2b companies apply. For example, Cawsey and Rowley [27] focused on social media strategies of b2b companies. By conducting semi-structured interviews with marketing professional from France, Ireland, UK and USA it was found that enhancing brand image, extending brand awareness and facilitating customer engagement were considered the most common social media objective. The study proposed b2b social media strategy framework which includes six components of a social media strategy: 1) monitoring and listening 2) empowering and engaging employees 3) creating compelling content 4) stimulating eWOM 5) evaluating and selecting channels 6) enhancing brand presence through integrating social media.

Kasper et al. [28] proposed the Social Media Matrix which helps companies to decide which social media activities to execute based on their corporate and communication goals. The matrix includes three parts. The first part is focusing on social media goals and task areas, which were identified and matched. The second part consists of five types of social media activities (content, interaction/dialog, listening and analysing, application and networking). The third part provides a structure to assess the suitability of each activity type on each social media platform for each goal. The matrix was successfully tested by assessing the German b2b sector by using expert interviews with practitioners.

McShane et al. [33] proposed social media strategies to influence online users' engagement with $\mathrm{b} 2 \mathrm{~b}$ companies. Taking into consideration fluency lens the study analysed Twitter feeds of top 50 social $\mathrm{b} 2 \mathrm{~b}$ brands to examine the influence of hashtags, text difficulty embedded media and message timing on user engagement, which was evaluated in terms of likes and retweets. It was found that hashtags and text difficulty 
are connected to lower levels of engagement while embedded media such as images and video improve the level of engagement.

Another study by Swani et al. [30] aimed to investigate message strategies which can help in promoting eWOM activity for b2b companies. By applying content analysis and Hierarchical Linear Modeling the study analysed 1143 wall post messages from 193 fortune 500 Facebook accounts. The study found that b2b account posts will be more effective if they include corporate brand names and avoid hard sell or explicitly commercial statement. Also, companies should use emotional sentiment in Facebook posts

Most of the studies investigated the strategies and content of social media communications of $b 2 b$ companies. However, the limited number of studies investigated the importance of CEO engagement on social media in companies strategies. Mudambi et al. [29] emphasise the importance of CEO of b2b companies to be present and active on social media. The study discusses the advantages of social media presence for CEO and how it will benefit the company. For example one of the benefits for CEO can be perceived as being more trustworthy and effective and non-social CEOs, which will benefit the company in increased customer trust. Mudambi et al. [29] also discussed the platforms CEO should use and posting frequencies depending on the content of the post.

\subsection{Social media use}

Most of the studies employed context analysis and surveys to investigate how b2b companies use social media. For example, Vasudevan and Kumar [22] investigated how b2b companies use social media by analysing 325 brand posts of Canon India, Epson India, and HP India on Linkedin, Facebook and Twitter. By employing content analysis the study found that most of the post has a combination of text and message. More than $50 \%$ of the posts were about product or brand centric. The study argued that likes proved to be an unreliable measure of engagement, while shares were considered more reliable metric. The reason was that likes had high spikes when brand posts were boosted during promotional activities.

Müller et al. [21] investigated social media use in the German automotive market. By suing online analysis of 10 most popular car manufacturers online social networks and surveys of 6 manufacturers, 42 car dealers, 199 buyers the study found that Social Media communication relations are widely established between manufacturers and (prospective) buyers and only partially established between car dealers and prospective buyers. In contrast to that, on the business-to-business (b2b) side, Social Media communication is rarely used. Social Online Networks (SONs) are the most popular Social Media channels employed by businesses. Manufacturers and car dealers focus their Social Media engagement, especially on Facebook. From the perspective of prospective buyers, however, forums are the most important source of information.

Moore et al. [20] investigated the use of social media between b2b and b2c salespeople. By using survey data from 395 sales professional from different industries they found that B2B sales managers use social selling tools significantly more frequently than $\mathrm{B} 2 \mathrm{C}$ managers and $\mathrm{B} 2 \mathrm{C}$ sales representatives while conducting sales 
presentations. Also, it was found that B2B managers used social selling tools significantly more frequently than all sales representatives while closing sales.

Katona and Sarvary [19] presented a case of using social media by Maersk-the largest container shipping company in the world. The case provided details on the programme launch and the integration strategy which focused on integrating the largely independent social media operation into the company's broader marketing efforts.

Keinänen and Kuivalainen [16] investigated factors affecting the use of social media by $\mathrm{b} 2 \mathrm{~b}$ customers by conducting an online survey among 82 key customer accounts of an information technology service company. Partial least squares path modeling was used to analysed the proposed hypotheses. It was found that social media private use, colleague support for using SM, age, job position affected the use of social media by $\mathrm{b} 2 \mathrm{~b}$ customers. The study also found that corporate culture, gender, easiness to use and perception of usability did not affect the use of social media by b2b customers.

\subsection{Measuring effectiveness of social media}

It is important for a business to be able to measure the effectiveness of social media by calculating return on investment (ROI). ROI is the relationship between profit and the investment that generate that profit. Some studies focused on the ways companies can measure ROI and the challenges they face. For example, Gazal et al. [31] investigated the adoption and measuring of the effectiveness of social media in the context of US forest industry by using organizational-level adoption framework and TAM. By using data from 166 companies it was found that $94 \%$ of respondents do not measure the ROI from social media use. The reason is that the use of social media in marketing is relatively new and companies do not possess the knowledge of measuring ROI from the use of social media. Companies mostly use quantitative metrics (number of site visits, number of social network friends, number of comments and profile views) and qualitative metrics (growth of relationships with the key audience, audience participation, moving from monologue to dialogue with consumers.

Another study by Michaelidou et al. [5] found that most of the companies do not evaluate the effectiveness of their SNS in supporting their brand. The most popular measures were the number of users joining the groups/discussion and the number of comments made.

\subsection{Social media tools}

Some studies proposed tools, which could be employed by companies to advance their use of social media. For example, Mehmet and Clarke [17] proposed Social Semiotic Multimodal (SSMM) framework that improved analysis of social media communications. This framework employs multimodal extensions to systemic functional linguistics enabling it to be applying to analysing non-language as well as language constituents of social media messages. Furthermore, the framework also utilises expansion theory to identify, categorise and analyse various marketing communication 
resources associated with marketing messages and also to reveal how conversations are chained together to form extended online marketing conversations. This semantic approach is exemplified using a Fairtrade Australia B2B case study demonstrating how marketing conversations can be mapped and analysed. The framework emphasises the importance of acknowledging the impact of all stakeholders, particularly messages that may distract or confuse the original purpose of the conversation.

Yang et al. [18] proposed the temporal analysis technique to identify user relationships on social media platforms. The experiment was conducted by using data from Digg.com. The results showed that the proposed techniques achieved substantially higher recall but not very good at precision. This technique will help companies to identify their future consumers based on their user relationships.

\section{$4 \quad$ Limitations and future research directions}

Studies on social media in the context of $\mathrm{b} 2 \mathrm{~b}$ companies have the following limitations. First, studies investigated the positive effect of social media such as consumer satisfaction, consumer engagement, and brand awareness. However, it will be interesting to consider the dark side of social media use such as an excessive number of request on social media to salespeople, which can result in the reduction of the responsiveness. Second, a limited number of studies discussed the way b2b companies can measure ROI. Future research should investigate how companies can measure intangible ROI, such as eWOM, brand awareness, and customer engagement [34]. Also, future research should investigate the reasons why most of the users do not assess the effectiveness of their SNS. Furthermore, most of the studies focused on likes, shares, and comments to evaluate social media engagement. Future research should focus on other types of measures. Third, studies were performed in China [23, 35], USA [36-38], India [21, 22, 39], UK [5, 37, 40]. It is strongly advised that future studies conduct research in other countries as findings can be different due to the culture and social media adoption rates. Future studies should pay particular attention to other emerging markets (such as Russia, Brazil, and South Africa) as they suffer from the slow adoption rate of social media marketing. Some companies in these countries still rely more on traditional media for advertising of their products and services, as they are more trusted in comparison with social media channels [41, 42]. Lastly, most of the studies on social media in the context of b2b companies use a cross-sectional approach to collect the data. Future research can use longitudinal approach to advance understanding of social media use and its impact over time.

\section{Conclusion}

The aim of this research was to provide a systematic review of the literature on the use of social media by $b 2 b$ companies. It was found that $b 2 b$ companies use social media, but not all companies consider it as part of their marketing strategies. The studies on social media in b2b context focused on the effect of social media, anteced- 
ents and barriers of adoption of social media, social media strategies, social media use, and measuring the effectiveness of social media.

The summary of the key observations provided from this literature review is the following:

- Facebook, Twitter and LinkedIn are the most famous social media platforms used by b2b companies.

- Social media has a positive effect on customer satisfaction.

- In systematically reviewing 70 publications on social media in the context of $\mathrm{b} 2 \mathrm{~b}$ companies it was observed that most of the studies use online surveys and online content analysis.

- Companies still look for ways to evaluate the effectiveness of social media.

- Innovativeness has a significant positive effect on companies' adoption to use social media.

- Lack of staff familiarity and technical skills are the main barriers affect adoption of social media by $b 2 b$.

This research has a number of limitations. First, only publications from the Scopus database were included in literature analysis and synthesis. Second, this research did not use a meta-analysis. To provide a broader picture of the research on social media in $b 2 b$ context and reconcile conflicting findings of the existing studies future research should conduct a meta-analysis. It will advance the knowledge of the social media domain.

\section{References}

1. Ismagilova, E., Dwivedi, Y.K., Slade, E., Williams, M.D.: Electronic word of mouth (eWOM) in the marketing context: A state of the art analysis and future directions. Springer (2017)

2. Alalwan, A.A., Rana, N.P., Dwivedi, Y.K., Algharabat, R.: Social media in marketing: A review and analysis of the existing literature. Telematics and Informatics 34, 1177-1190 (2017)

3. Barreda, A.A., Bilgihan, A., Nusair, K., Okumus, F.: Generating brand awareness in online social networks. Computers in human behavior 50, 600-609 (2015)

4. Salo, J.: Social media research in the industrial marketing field: Review of literature and future research directions. Industrial Marketing Management 66, 115-129 (2017)

5. Michaelidou, N., Siamagka, N.T., Christodoulides, G.: Usage, barriers and measurement of social media marketing: An exploratory investigation of small and medium B2B brands. Industrial marketing management 40, 1153-1159 (2011)

6. Juntunen, M., Ismagilova, E., Oikarinen, E.-L.: B2B brands on Twitter: Engaging users with a varying combination of social media content objectives, strategies, and tactics. Industrial Marketing Management (2019)

7. Pascucci, F., Ancillai, C., Cardinali, S.: Exploring antecedents of social media usage in B2B: a systematic review. Management Research Review 41, 629-656 (2018)

8. Ismagilova, E., Hughes, L., Dwivedi, Y.K., Raman, K.R.: Smart cities: Advances in research-An information systems perspective. International Journal of Information Management 47, 88-100 (2019) 
9. Williams, M.D., Rana, N.P., Dwivedi, Y.K.: The unified theory of acceptance and use of technology (UTAUT): a literature review. Journal of Enterprise Information Management 28, 443-488 (2015)

10.Agnihotri, R., Dingus, R., Hu, M.Y., Krush, M.T.: Social media: Influencing customer satisfaction in B2B sales. Industrial Marketing Management 53, 172-180 (2016)

11.Agnihotri, R., Kothandaraman, P., Kashyap, R., Singh, R.: Bringing "social” into sales: The impact of salespeople's social media use on service behaviors and value creation. Journal of Personal Selling \& Sales Management 32, 333-348 (2012)

12.Hsiao, S.-H., Wang, Y.-Y., Wang, T., Kao, T.-W.: How social media shapes the fashion industry: The spillover effects between private labels and national brands. Industrial Marketing Management (2019)

13.Itani, O.S., Agnihotri, R., Dingus, R.: Social media use in B2b sales and its impact on competitive intelligence collection and adaptive selling: Examining the role of learning orientation as an enabler. Industrial Marketing Management 66, 64-79 (2017)

14.Meire, M., Ballings, M., Van den Poel, D.: The added value of social media data in B2B customer acquisition systems: A real-life experiment. Decision Support Systems 104, 26-37 (2017)

15.Rodriguez, M., Peterson, R.M., Krishnan, V.: Social media's influence on business-tobusiness sales performance. Journal of Personal Selling \& Sales Management 32, 365-378 (2012)

16.Keinänen, H., Kuivalainen, O.: Antecedents of social media B2B use in industrial marketing context: customers' view. Journal of Business \& Industrial Marketing 30, 711-722 (2015)

17.Mehmet, M.I., Clarke, R.J.: B2B social media semantics: Analysing multimodal online meanings in marketing conversations. Industrial Marketing Management 54, 92-106 (2016)

18.Yang, C.C., Yang, H., Tang, X., Jiang, L.: Identifying implicit relationships between social media users to support social commerce. In: Proceedings of the 14th Annual International Conference on Electronic Commerce, pp. 41-47. ACM, (Year)

19.Katona, Z., Sarvary, M.: Maersk Line: B2B Social Media-“It's Communication, Not Marketing". California management review 56, 142-156 (2014)

20.Moore, J.N., Raymond, M.A., Hopkins, C.D.: Social selling: A comparison of social media usage across process stage, markets, and sales job functions. Journal of Marketing Theory and Practice 23, 1-20 (2015)

21.Müller, L., Griesbaum, J., Mandl, T.: Social media relations in the german automotive market. In: IADIS International Conference ICT, Society and Human Beings, pp. 19-26. IADIS Press (Year)

22.Vasudevan, S., Kumar, F.J.P.: Social media and B2B brands: An indian perspective. International Journal of Mechanical Engineering and Technology 9, 767-775 (2018)

23.Lacka, E., Chong, A.: Usability perspective on social media sites' adoption in the B2B context. Industrial Marketing Management 54, 80-91 (2016)

24.Lashgari, M., Sutton-Brady, C., Solberg Søilen, K., Ulfvengren, P.: Adoption strategies of social media in B2B firms: a multiple case study approach. Journal of Business \& Industrial Marketing 33, 730-743 (2018)

25.Müller, J.M., Pommeranz, B., Weisser, J., Voigt, K.-I.: Digital, Social Media, and Mobile Marketing in industrial buying: Still in need of customer segmentation? Empirical evidence from Poland and Germany. Industrial Marketing Management 73, 70-83 (2018) 
26.Shaltoni, A.M.: From websites to social media: exploring the adoption of internet marketing in emerging industrial markets. Journal of Business \& Industrial Marketing 32, 1009-1019 (2017)

27.Cawsey, T., Rowley, J.: Social media brand building strategies in B2B companies. Marketing Intelligence \& Planning 34, 754-776 (2016)

28.Kasper, H., Koleva, I., Kett, H.: Social Media Matrix Matching Corporate Goals with External Social Media Activities. In: Extended Semantic Web Conference, pp. 233-244. Springer, (Year)

29.Mudambi, S.M., Sinha, J.I., Taylor, D.S.: Why B-to-B CEOs Should Be More Social on Social Media. Journal of Business-to-Business Marketing 26, 103-105 (2019)

30.Swani, K., Milne, G., P. Brown, B.: Spreading the word through likes on Facebook: Evaluating the message strategy effectiveness of Fortune 500 companies. Journal of Research in Interactive Marketing 7, 269-294 (2013)

31.Gazal, K., Montague, I., Poudel, R., Wiedenbeck, J.: Forest products industry in a digital age: Factors affecting social media adoption. Forest Products Journal 66, 343-353 (2016)

32.Kho, N.D.: B2B gets social media. EContent 31, 26-30 (2008)

33.McShane, L., Pancer, E., Poole, M.: The Influence of B to B Social Media Message Features on Brand Engagement: A Fluency Perspective. Journal of Business-to-Business Marketing 26, $1-18(2019)$

34.Kumar, V., Mirchandani, R.: Increasing the ROI of social media marketing. MIT sloan management review 54, 55 (2012)

35.Niedermeier, K.E., Wang, E., Zhang, X.: The use of social media among business-tobusiness sales professionals in China: how social media helps create and solidify guanxi relationships between sales professionals and customers. Journal of Research in Interactive Marketing 10, 33-49 (2016)

36.Guesalaga, R.: The use of social media in sales: Individual and organizational antecedents, and the role of customer engagement in social media. Industrial Marketing Management 54, 7179 (2016)

37.Iankova, S., Davies, I., Archer-Brown, C., Marder, B., Yau, A.: A comparison of social media marketing between B2B, B2C and mixed business models. Industrial Marketing Management (2018)

38.Ogilvie, J., Agnihotri, R., Rapp, A., Trainor, K.: Social media technology use and salesperson performance: A two study examination of the role of salesperson behaviors, characteristics, and training. Industrial Marketing Management 75, 55-65 (2018)

39.Agnihotri, R., Trainor, K.J., Itani, O.S., Rodriguez, M.: Examining the role of sales-based CRM technology and social media use on post-sale service behaviors in India. Journal of Business Research 81, 144-154 (2017)

40.Bolat, E., Kooli, K., Wright, L.T.: Businesses and mobile social media capability. Journal of Business \& Industrial Marketing 31, 971-981 (2016)

41.Ali, Z., Shabbir, M.A., Rauf, M., Hussain, A.: To Assess the Impact of Social Media Marketing on Consumer Perception. International Journal of Academic Research in Accounting, Finance and Management Sciences 6, 69-77 (2016)

42.Olotewo, J.: Social media marketing in emerging markets. International Journal of Online Marketing Research 2, 10 (2016) 